\title{
A Importância do Ensino de Climatologia nas Ações de Defesa Civil em Regiões de Vulnerabilidade Socioeconômica de Fortaleza/CE
}

\author{
Emerson Mariano da Silva ${ }^{1}$ (D), Francisco Claudio Costa de Freitas ${ }^{1,2}$, \\ Leonidas Rodrigues Barreto Neto ${ }^{1,2}$, Adnamar Ferreira Girão ${ }^{1,3}$, \\ Clicério Aderaldo Pinheiro Garcia ${ }^{1,3}$, Luis Uchôa Pinho ${ }^{1,3}$, Pedro Ananias Gomes Catanho ${ }^{1,4}$ \\ ${ }^{1}$ Mestrado Profissional em Climatologia e Aplicações nos Países da CPLP e África, \\ Universidade Estadual do Ceará, Fortaleza, CE, Brasil. \\ ${ }^{2}$ Secretaria Municipal de Educação, Fortaleza, CE, Brasil. \\ ${ }^{3}$ Coordenadoria Municipal de Proteção e Defesa Civil, Fortaleza, CE, Brasil. \\ ${ }^{4}$ Coordenadoria Estadual de Defesa Civil do Ceará, Fortaleza, CE, Brasil.
}

Recebido em: 30 de Abril de 2019 - Aceito em: 27 de Maio de 2019

\begin{abstract}
Resumo
Apresentam-se os resultados de estudos realizados com o objetivo de investigar a relação da importância do ensino de climatologia nas escolas e comunidades com as ações de defesa civil em regiões de vulnerabilidade socioeconômica de Fortaleza/CE. Os resultados mostram que, em maioria, estudantes e professores, afirmam a importância da formação em climatologia, apesar das dificuldades encontradas com o material didático usado e a falta de eventos científicos que abordem a temática nas escolas, para o entendimento e a mitigação dos efeitos dos desastres naturais nas comunidades investigadas. Em adição, observou-se que as áreas em estudo apresentam correlação estatística positiva e forte entre o aumento das chuvas observadas e as ocorrências de desastres nas comunidades e que a formação em Climatologia e Defesa Civil pode auxiliar no processo da Gestão integrada de Riscos e Desastres (GIRD) com participação efetiva dessas comunidades.
\end{abstract}

Palavras-chave: climatologia, docência, desastres naturais.

\section{The Importance of Teaching Climatology in Civil Defense Actions in Regions of Socioeconomic Vulnerability of Fortaleza/CE}

\begin{abstract}
The results of studies carried out with the objective of investigating the relation of the importance of teaching climatology in schools and communities with the actions of civil defense in regions of socioeconomic vulnerability of Fortaleza/ $\mathrm{CE}$ are presented. The results show that the majority of students and teachers affirm the importance of training in climatology, despite the difficulties encountered with the didactic material used and the lack of scientific events that approach the theme in the schools, for the understanding and the mitigation of the effects natural disasters in the communities investigated. In addition, it was observed that the areas under study present a positive and strong statistical correlation between the increase of observed rains and the occurrence of disasters in the communities and that the training in Climatology and Civil Defense can assist in the process of Integrated Risk and Disaster Management (GIRD) with effective participation of these communities.
\end{abstract}

Keywords: climatology, teaching, natural disasters.

\section{Introdução}

A compreensão dos conceitos que envolvem os estudos do tempo meteorológico e do clima (climatologia) tornam-se cada vez mais necessários e, aos poucos, vem sendo incorporado ao cotidiano das pessoas em diferentes segmentos, tais como na economia, na indústria, no

Autor de correspondência: Emerson Mariano da Silva, emerson.mariano@uece.br. 
comércio e na prevenção, monitoramento e mitigação dos efeitos de desastres naturais, denominada de Gestão Integrada de Risco de Desastres.

Conforme Ayoade (2003) é preciso compreender que no mundo contemporâneo os estudos do tempo e do clima ocupam uma posição central e importante no amplo campo da ciência ambiental porque os processos atmosféricos influenciam outros fenômenos nas outras partes do ambiente, principalmente na biosfera, hidrosfera e litosfera.

Steinke (2012) e Dantas (2016) concordam que o ensino dos conteúdos da climatologia na escola se torna mais interessante quando vinculamos o que aprendemos nos livros com nossa realidade. Assim, o professor dessa disciplina, no ensino fundamental, médio ou superior, como nos cursos de graduação em Meteorologia e Geografia, tem o importante papel de aproximar os conteúdos contidos nos livros didáticos com o que os estudantes observam em seu cotidiano.

Meneguzzo e Meneguzzo (2010) vão além das ideias apresentadas acima, em que mencionam os conteúdos de climatologia devem ser discutidos para que haja a compreensão da dinâmica atmosférica e de outros elementos que regulam o clima, assim reveste-se na particular importância de compreender também como as atividade antrópicas podem causar consequências no clima presente e futuro do planeta, ou seja, a compreensão de como essas atividades influenciam nas mudanças climáticas globais e regionais.

Assim, afirma-se que o estudo do clima pode ampliar a visão crítica dos estudantes de diferentes níveis escolares e levá-los a realizar reflexões individuais ou em grupos a respeito de questões ambientais e socioambientais, entre outras, bem como despertar para a preservação dos desastres naturais relacionados ao clima na região em que vivem e a Gestão Integrada de Risco de Desastres (GIRD).

Nesse contexto, o presente trabalho tem como objetivo investigar a relação entre as práticas do ensino de climatologia, nos níveis fundamentais e superior, e a formação nas comunidades, como elementos transformadores para auxiliar na identificação, monitoramento e mitigação dos efeitos dos desastres naturais na região de Fortaleza/ CE.

\subsection{O ensino de climatologia e a prática docente nas escolas públicas}

Autores mencionam que os problemas relacionados ao processo de ensino-aprendizagem dos conteúdos de climatologia decorrem da formação inicial e em nível superior do estudante que por sua vez tem consequências na prática docente em sala de aula (Fortuna, 2010; Melo, 2015).

O processo de ensino-aprendizagem citado acima é composto por um complexo sistema de interações comportamentais entre professores e estudantes, sendo mais do que ensinar ou aprender como se fossem processos independentes da ação humana (Kubo e Botomé, 2001).

Nesse contexto, é importante observar que o primeiro desafio é a formação inicial do professor de geografia na universidade. Autores mencionam que faltam entendimentos dos conteúdos de climatologia por esses professores e estudantes e isto se reflete nas salas de aula dos ensinos fundamental. Os autores também concordam com a hipótese de que esse problema esteja associado a precariedade do ensino no país em seus diferentes níveis (Oliveira et al., 2012).

A importância da identificação desses problemas metodológicos e de formação dos professores que atuam em particular no ensino fundamental ministrando conteúdos de Meteorologia e Climatologia é de levar os atores envolvidos nas instituições de ensino superior e secretarias de educação dos municípios e estados a uma reflexão sobre a formação e a prática docente, bem como dos conteúdos e da qualidade dos livros didáticos adotados para esse fim.

As transformações pelas quais tem passado o ensino e a própria forma de compreender a realidade colocam o espaço da escola e da universidade como o ambiente de conciliação. Segundo Cavalcanti (2002) a escola é um lugar de encontro de culturas, de saberes, de saberes científicos e de saberes cotidianos, ainda que o seu trabalho tenha como referência básica os saberes científicos. Assim, a reflexão crítica entre a formação dos professores na universidade e a prática docente certamente trará melhorias no processo de ensino-aprendizagem dos conteúdos de Climatologia, nos ensinos fundamental, médio e superior.

\subsection{A relação entre ensino de climatologia, a Defesa Civil e a GIRD}

A defesa civil trabalha desenvolvendo ações destinadas à prevenção, a mitigação dos efeitos e resposta aos desastres, bem como para reconstrução da área atingida por esses. Para conseguir máxima efetividade nessas ações é necessário o envolvimento da sociedade de forma ativa e consciente (PNPDC - Lei 12.608/2012).

Calheiros (2009) afirma que o país não possui uma cultura de defesa civil e que isso é consequência da inexistência da preocupação em preparar a população para o enfrentamento das consequências dos desastres naturais, e assim, permitir que a sociedade participe efetivamente do direito e do dever de cidadão assegurados no Plano Nacional de Proteção e Defesa Civil (PNPDC) - Lei 12.608/ 2012.

Em geral, autores classificam de desastres naturais quando os desastres são provocados por fenômenos e desequilíbrios da natureza e quando esses fenômenos atingem áreas ou regiões habitadas pelo homem, causando-lhe danos (Castro e Calheiros, 2007; Tominaga et al., 2009).

A GIRD é definida de forma genérica. Autores referem-se a um processo social cuja finalidade é a 
previsão, a redução e o controle permanente dos fatores de risco de desastre na sociedade, e o resultado são planos de intervenção em níveis distintos, desde planos globais a comunitários e familiares, que visam o desenvolvimento humano, econômico, ambiental e territorial, sustentáveis (Narváez et al., 2009).

Ainda mencionam que a GIRD requer a existência de sistemas ou estruturas organizacionais e institucionais com coordenação estabelecidas e papéis diferenciados e pactuados entre os representantes das instituições e da sociedade civil, uma instâncias coletiva de representação social dos diferentes atores e interesses que adquirem papeis importantes no processo de construção da compreensão do risco e da sua redução, previsão e controle.

Amaral e Gutjahr (2011) acrescentam que a GIRD deve ser integrada a outras políticas públicas para cumprir sua finalidade de reduzir e prevenir o risco de desastres na sociedade. Mencionam que o gerenciamento do risco de desastres deve partir do entendimento dos fenômenos naturais locais de forma a se preparar a comunidade para enfrentar as consequências desses fenômenos. Os autores ainda mencionam a hipótese de que a forma mais eficiente de sobreviver aos desastres naturais é reconhecer os sinais prévios e ter um plano de enfrentamento caso aconteça.

Concordando-se com esses argumentos, mencionase que para isto deve-se capacitar a comunidade (adultos, idosos e crianças) apresentando-lhes as características dos fenômenos naturais que thes afetam e pactuando-se os planos de ações dentro dos níveis definidos na GIRD.

Nesse contexto, as universidades e escolas exercem um papel fundamental na formação de pessoas na sociedade que possam compreender a relação entre as variações do clima global e regional e os desastres naturais que afetam suas vidas em comunidade. Como por exemplo, os estudantes que moram em comunidades classificadas como área de risco (morros, beira de rios, riachos, lagoas e área das praias ocupadas desordenadamente) e a convivência com as ocorrências de desastres naturais como alagamentos e/ou inundações. Atividades previstas na Lei de Diretrizes e Base da Educação Brasileira (LDB), especificamente nas definições do ensino de temas transversais, tais como defesa civil e meio ambiente ( $\$ 7^{\circ}$ do Art. 26).

Assim, da formação acadêmica em climatologia tem-se uma outra possibilidade de formação complementar para a comunidade através da capacitação ministrada por agentes de defesa civil em cursos de noções básicas de defesa civil e Gestão Integrada de Riscos de Desastres (GIRD) para que a comunidade possa auxiliar as famílias que são atingidas por desastres de forma rápida, eficiente $\mathrm{e}$ segura.

\section{Materiais e Métodos}

Visando cumprir o objetivo proposto no trabalho foram realizados estudos de caso sobre o ensino dos conteúdos de climatologia em escolas públicas de Fortaleza/CE, incluindo a análise dos conteúdos didáticos de climatologia apresentados nos livros didáticos de geografia do ensino fundamental, contidos no Programa Nacional do Livro Didático (PNLD). Em adição, realizou-se um diagnóstico da formação dos professores de Geografia na Universidade Estadual do Cerará (UECE), especificamente em conteúdos de Climatologia e em Gestão Integrada de Risco de Desastres - GIRD.

Ainda foram realizados estudos de caso sobre a importância do ensino de climatologia nas ações da defesa civil e seu papel como formação para a prevenção de desastres naturais nas áreas de riscos do município de Fortaleza/CE.

Nos estudos foram usados questionários para a coleta de dados, devidamente autorizados pelas direções da escolas públicas participantes da pesquisa e no caso do ensino superior, devidamente autorizados pelos estudantes participantes da pesquisa, além de dados climatológicos das precipitações pluviométricas sobre a região de Fortaleza/CE, cedidos pela Fundação Cearense de Meteorologia e Recursos Hídricos (FUNCEME), informações de ocorrências de desastres naturais (alagamento e inundações) obtidas na Coordenadoria Especial de Proteção e Defesa Civil de Fortaleza/CE, e apresentações de palestras e cursos de curta duração sobre as ações da Defesa Civil como formação para a comunidade, com conteúdos de climatologia e mudanças climáticas, educação ambiental e desenvolvimento sustentável.

\section{Resultados e Discussões}

\subsection{Ensino de climatologia nas escolas públicas de Fortaleza/CE}

Primeiro, aplicou-se um questionário para coletar informações em dez escolas públicas em áreas com grande agravamento de problemas sociais, econômicos e estruturais. Ao todo foram aplicados 68 (sessenta e oito) questionários, sendo 18 (dezoito) aplicados aos docentes e 50 (cinquenta) aplicado aos discentes dessas escolas. A seguir nas Figs. 1 e 2 são apresentados uma compilação dos resultados das respostas dos questionários aplicados aos docentes e discentes das escolas.

Observa-se que, apesar das discussões sobre o clima e as mudanças climáticas serem uma realidade na sociedade atual, em particular depois da grande divulgação na imprensa dos resultados obtidos pelo Painel Intergovernamental sobre Mudanças Climáticas (IPCC), da Sociedade Brasileira de Meteorologia (SBMET) e das universidades públicas buscarem refletir sobre as questões climáticas e ambientais em eventos científicos, aproximadamente $44 \%$ dos professores afirmam ter discussões sobre essas questões em suas aulas de climatologia no ensino fundamental 


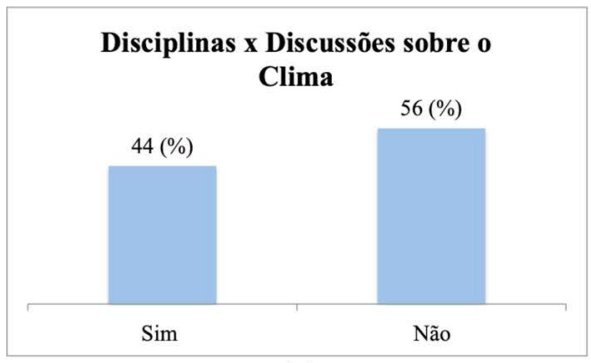

(a)

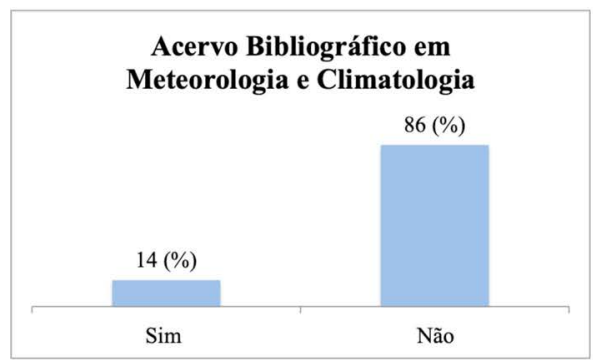

(c)

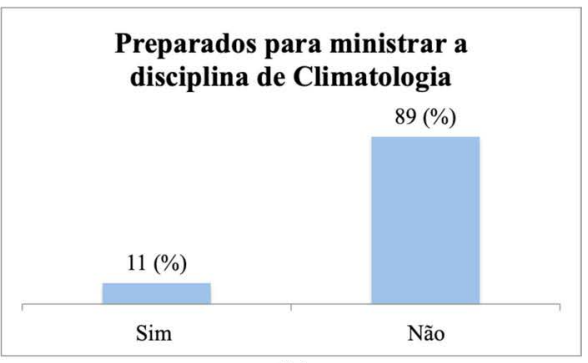

(b)

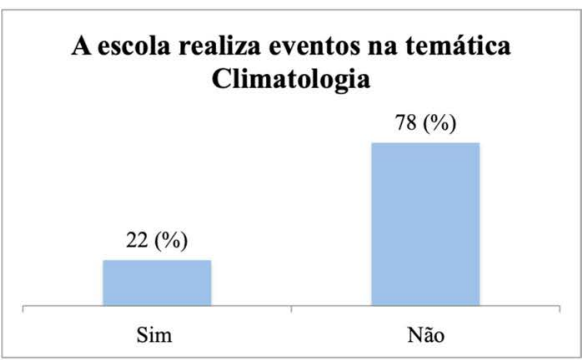

(d)

Figura 1 - Respostas dos questionários aplicados aos docentes nas escolas públicas na região da Secretaria Executiva Regional V em Fortaleza/CE.

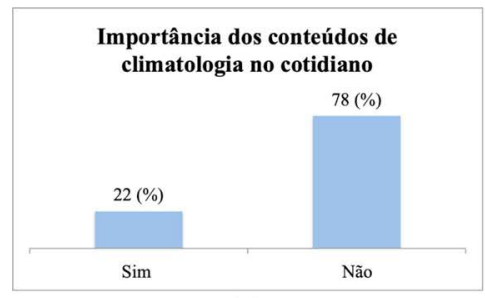

(a)

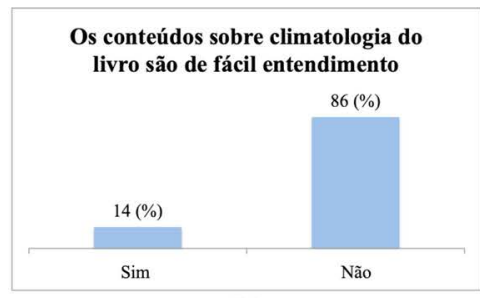

(b)

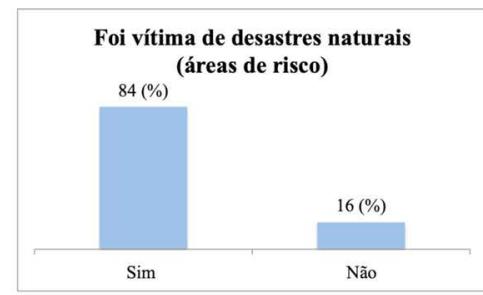

(c)

Figura 2 - Respostas dos questionários aplicados aos estudantes nas escolas públicas na região da Secretaria Executiva Regional Vem Fortaleza/CE.

(Fig. 1a) e apenas $22 \%$ afirmam ter eventos dessa natureza em suas escolas (Fig. 1d).

Em relação a formação acadêmica dos professores e o acervo bibliográfico disponíveis nas escolas publicas investigadas, encontra-se que apenas $11 \%$ desses se sentem preparados para ministrar os conteúdos de Meteorologia e Climatologia no ensino fundamental (Fig. 1b) e $86 \%$ dos professores afirmam não ter material bibliográfico adequado para ministrar esses conteúdos (Fig. 1c).

A Fig. 2 mostra os resultados dos questionários aplicados aos estudantes dessas escolas. Observa-se que os professores das escolas não conseguem motivar seus estudantes em relação a perceber a importância dos estudos sobre o clima e a relação com o cotidiana da sociedade, assim, 78\% dos estudantes afirmam não terem consciência da importância dos conteúdos de climatologia em seus cotidianos (Fig. 2a), apesar de $84 \%$ desses estudantes afirmarem ter sido vítima de desastres naturais e terem moradia em áreas de risco nos bairros da Regional $\mathrm{V}$ de Fortaleza/CE (Fig. 2c).
Em relação a facilidade dos conteúdos apresentados nos livros didáticos, apenas $14 \%$ responderam que tem facilidade de entender os conteúdos e $86 \%$ afirmam que os conteúdos não são de fácil entendimento. Esse fato, aliado a precariedade do acervo bibliográfico nessas escolas, mostrado nas respostas dos professores, com certeza, traz dificuldades para o processo de ensino-aprendizagem desses conteúdos nessa faixa etária e, consequentemente, deve trazer dificuldades na aprendizagem desses conteúdos no ensino superior, concordando com as hipóteses descritas pelos autores usados como referencia nesse artigo (seção introdutória).

Segundo, foi aplicado um questionário aos vinte e três professores de Geografia do $6^{\circ}$ ano das escolas de ensino fundamental na região da Secretaria Regional IV do Município de Fortaleza/CE com o objetivo de diagnosticar a avaliação dos conteúdos de Climatologia dos livros didáticos propostos pelo Plano Nacional do Livro Didático (PNLD).

A abordagem metodológica aos professores nas escolas dessa região da cidade foi semelhante a realizada 
aos professores das escolas da Regional V, os resultados também vão de encontro ao observado na análise anterior, ou seja, a minoria (39\%) dos professores estão satisfeitos com os conteúdos apresentados nos livros didáticos propostos pelo PLND, apesar de $87(\%)$ desses professores se posicionarem pela importância desses conteúdos no ensino fundamental (Fig. 3).

Sobre a análise dos conteúdos de Climatologia nos livros didáticos propostos pelo PNLD, foram propostas seis fichas avaliativas (adaptadas) em tabelas que indicam desde o título do livro, o(s) capítulo(s) que abordam os conteúdos de Climatologia, os conteúdos fatuais/conceituais, os conteúdos procedimentais e os conteúdos atitudinais, baseado nas propostas de definições de conteúdos de Zabala (1998) e Barbosa e Oliveira (2012).

Os resultados mostraram que quatro dos seis livros apresentam dois capítulo com conteúdos relacionados a Climatologia e os outros dois apresentam três capítulos com esses conteúdos.

Alguns desses livros trazem capítulos com os conteúdos de Climatologia associados aos conteúdos relativos a vegetação e as paisagens, as atividades econômicas e os problemas ambientais, poluição atmosférica, classificação climática, as ações antrópicas e as mudanças climáticas. Outros, trazem capítulos fora do contexto, como o clima e a dinâmica dos rios e onde fica nosso planeta.

Terceiro, investigou-se uma amostra aleatória de 15 estudantes curso de Licenciatura em Geografia da UECE, que concordaram em responder 23 questões sobre formação acadêmica. As questões foram definidas com o objetivo de diagnosticar a importância da inserção dos conteúdos GIRD na grade curricular do curso, já que o curso conta com uma disciplina de Climatologia.

A Fig. 4 mostra as respostas dos estudantes ao questionário aplicado. Apresenta-se como resultado apenas as questões eleitas como mais relevantes para a estudo em questão. Assim, observa-se que $100 \%$ dos estudantes mostram ter conhecimento das mudanças climáticas e da relação dessas alterações no clima global e regional com os desastres naturais, sendo que $73 \%$ desses concordam fortemente e $27 \%$ concordam.

Em relação ao conhecimento das premissas da Defesa Civil e da Gestão Integrada de Riscos e Desastres
(GIRD), aproximadamente $73 \%$ dos estudantes afirmam ter conhecimentos sobre a GIRD e apenas $40 \%$ do total afirma ter conhecimento dos processos sistêmicos da GIRD.

Ressalta-se que os processos sistêmicos para otimizar as cinco fases da proteção e defesa civil da sociedade são: prevenção, mitigação, resposta, reabilitação e reconstrução. Todos devem está inseridos nas políticas públicas setoriais de habitação, segurança, saúde e educação, nos três níveis de governo: federal, estadual e municipal.

Observa-se, também, que $73 \%$ dos estudantes são favoráveis a inclusão da disciplina com esses conteúdos na grade curricular do curso. Assim, acredita-se que juntamente com os conteúdos da disciplina de Climatologia, esses estudantes de do curso de licenciatura em geografia possam ter uma melhor formação nessa área e, consequentemente, ajudar a elevar o nível do processo de ensinoaprendizagem nas escolas públicas do ensino fundamental em Fortaleza/CE (Fig. 4).

\subsection{Climatologia e as ações de Defesa Civil em Fortaleza/CE}

Na Fig. 5 apresentam-se a correlação estatística entre duas séries de dados das tipologias de desastres naturais (alagamento e inundação) e as chuvas observadas na cidade de Fortaleza/CE no período de 2013 a 2017, nos meses de janeiro a junho, período em que se observam a maior quantidade de chuvas na região (Silva et. al., 2007).

As definições de alagamento e inundações referemse ao acúmulo momentâneo de águas em um determinado local, decorrente de problemas de drenagem pluvial e extravasamento das águas do corpo hídrico para suas áreas marginais, respectivamente (Carvalho et. al., 2007; Julião et. al, 2009).

Nesse contexto, observam-se que as correlações estatísticas entre as chuvas observadas na região e o casos de alagamentos e inundações são positivas $(0,70$ e 0,76$)$ e classificadas como fortes (Devore, 2006). Ou seja, tem-se que, em geral, quanto maior o volume de chuvas mais ocorrências dessa natureza serão observadas.

Constatando-se a característica geral das ocorrências de alagamentos e inundações na região, partiu-se para uma outra investigação através de um recorte feito para a região

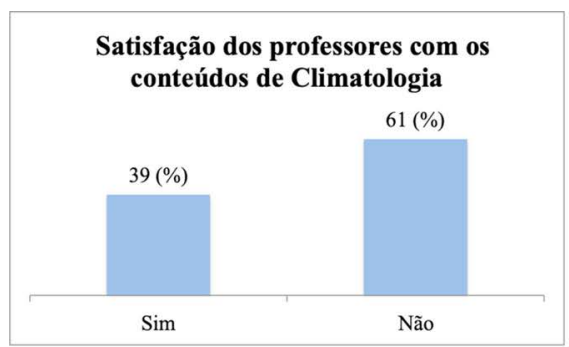

(a)

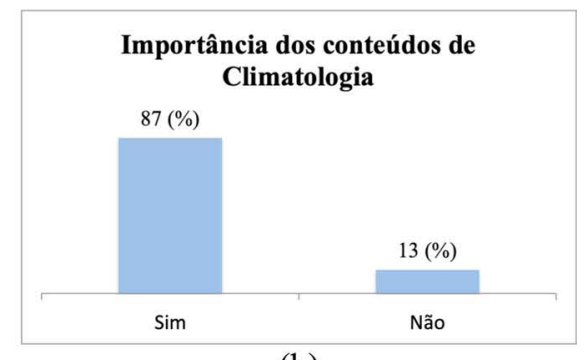

(b)

Figura 3 - Respostas dos questionários aplicados aos docentes nas escolas públicas na região da Secretaria Executiva Regional IV em Fortaleza/CE. 


\section{Percentual das respostas $(\%)$ \\ Questinário aplicado aos estudantes do Curso de Geografia da UECE}
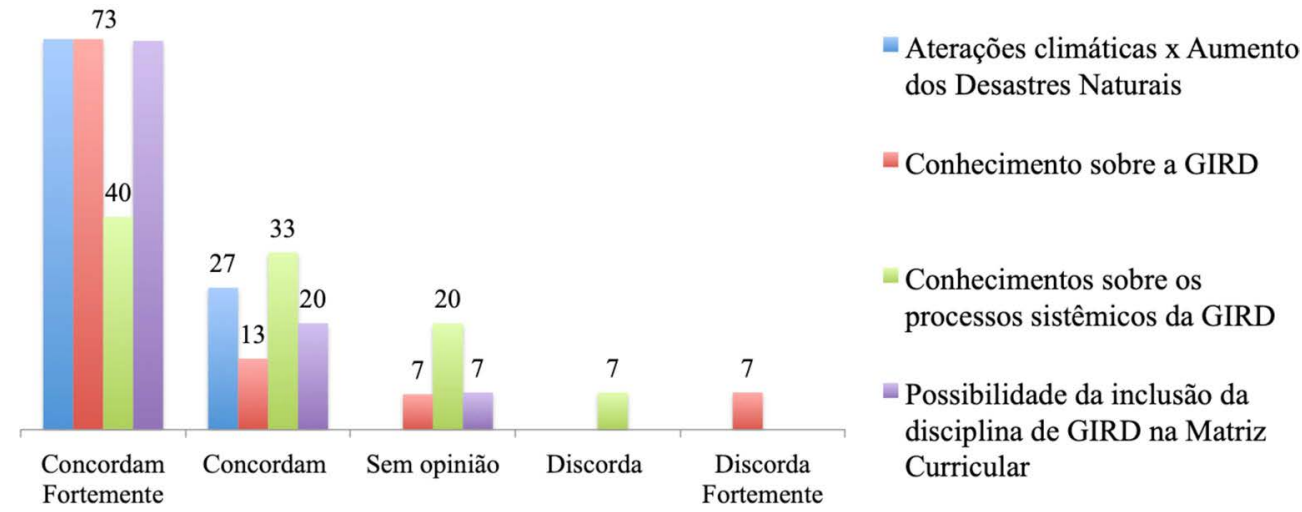

Figura 4 - Respostas dos estudantes do curso de Geografia da UECE.

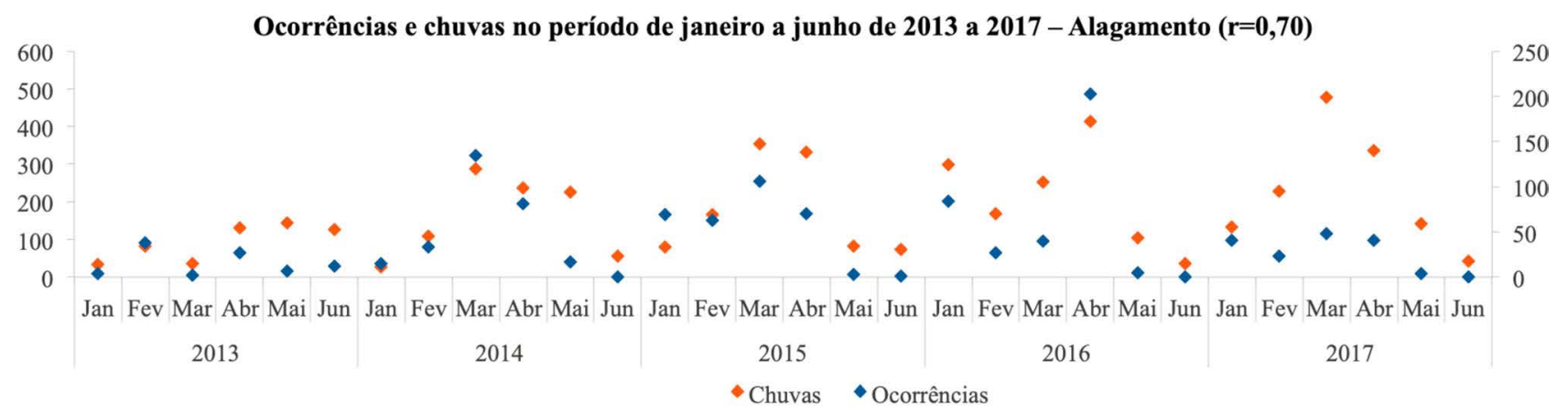

(a)

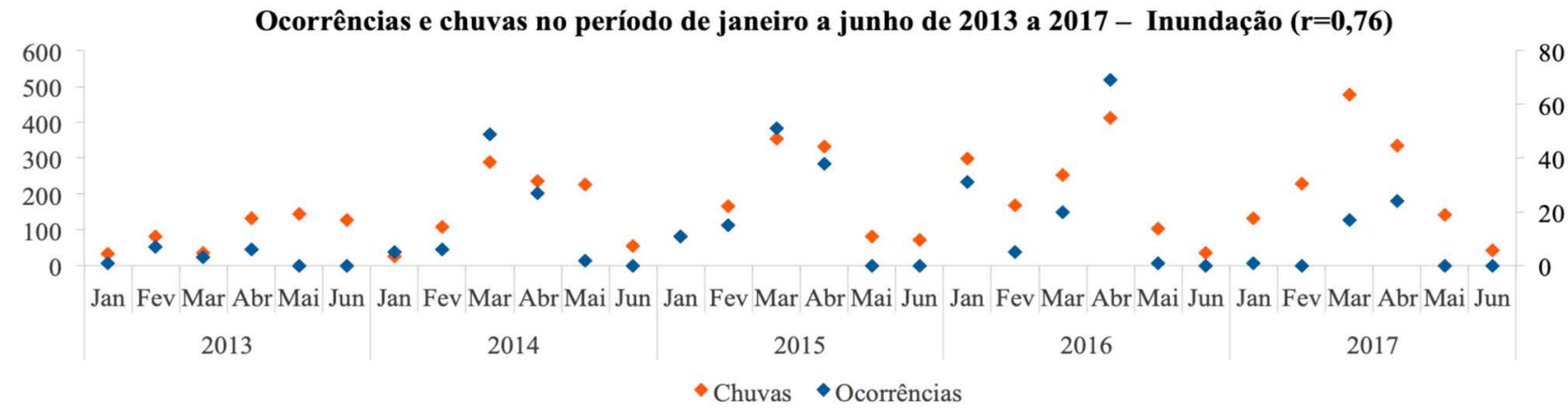

(b)

Figura 5 - Total de ocorrências e de chuvas no período de janeiro a junho dos anos de 2013 a 2017 e o coeficiente de correlação de Pearson (Devore, 2006).

da Secretaria Regional III de Fortaleza/CE, em particular para a área classificada como de risco - Ilha Dourada.

Ressalta-se que uma área classificada de risco é passível de ser atingida por fenômenos ou processos naturais e/ou induzidos que causem efeito adverso. Assim, as pessoas que habitam essas áreas estão sujeitas a danos à integridade física, perdas materiais e patrimoniais. Normalmente, no contexto das cidades brasileiras, essas áreas correspondem a núcleos habitacionais de baixa renda, e não são recomendáveis para a construção de moradias (Mota, 2007).

Na Fig. 6 encontram-se os percentuais das chuvas mensais em relação ao total da quadra chuvosa (fevereiro a maio) e o percentual das ocorrências mensais em relação ao total do período para os anos de 2014 a 2017.

Observam-se que, em geral, quanto o maior o percentual das chuvas mensais em relação ao total da quadra chuvosa, maior é o percentual do número de ocorrências 
observadas na região. Assim, encontram-se nos meses mais chuvosos (março e abril) os maiores registros de ocorrências de alagamentos e inundações.

A série do total de ocorrências mensais dos desastres por tipificação no período da quadra chuvosa dos anos de 2014 a 2017 na região da SERIII em Fortaleza/CE é mostrada na Fig. 7.

No período avaliado o numero de ocorrências variou de 80 (2017) a 127 (2015) em suas diversas tipologias classificadas pela defesa civil, sendo que, para a região em estudo, o número de alagamentos são sempre significantes, pois influenciam diretamente no número de ocorrência de risco de desabamentos na área de risco da Ilha Dourada.

Fato importante a se considerar é que nesses anos observaram-se desvios negativos no total das chuvas do período chuvoso em relação a média climatológica: em 2014 de 17,6\%, em 2015 de -10,6\% e em 2016 de aproximadamente $-10 \%$. Sendo que em 2017 observou-se um desvio positivo de aproximadamente $12 \%$ e o menor número de geral de ocorrências do período, apesar de 19 casos de alagamentos. Acredita-se que esse resultado tenha sido por conta do trabalho de capacitação dos agentes de defesa civil na comunidade.

Após os diagnósticos das correlações estáticas entre as chuvas e as ocorrências de alagamentos e inundações, descritas nos resultados acima e que são recortes de mais duas dissertações do estudantes do grupo, um outro estudante realizou uma série de palestras e oficinas como elemento formador e de prevenção dos desastres naturais ocorridos na região de Secretarias Regionais IV e V em Fortaleza/CE.

A escola cedida para as formações está localizada aproximadamente a duzentos metros do Rio Maranguapinho e inserida na área de risco de inundação e alagamento,

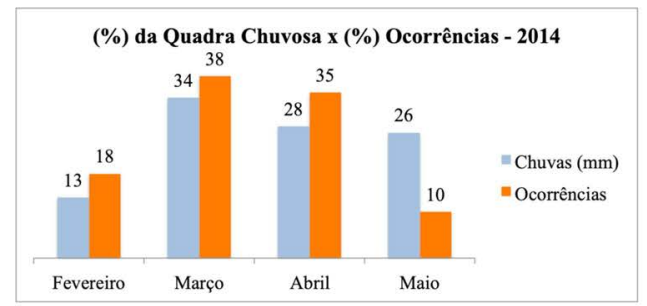

(a)

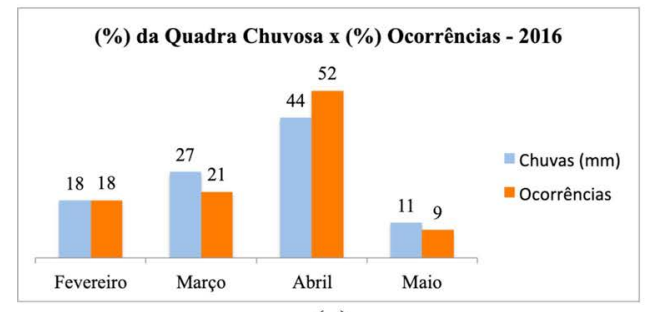

(c) conforme classificação da Defesa Civil de Fortaleza/CE (Fig. 8). As apresentações contaram com presenças de cento e cinquenta estudantes das séries finais do ensino fundamental da Educação de Jovens e Adultos (EJA) dessas regiões.

Foram abordados os conceitos e definições das ações da defesa civil, de climatologia e de mudanças climáticas, de educação ambiental e desenvolvimento sustentável, bem como da GIRD, através de estratégias didáticas motivadoras com experimentos que usam materiais de baixo custo e exemplificação de casos das ocorrências atendidas pela Defesa Civil de Fortaleza/CE.

$\mathrm{Na}$ Fig. 9 encontram-se algumas das questões trabalhadas nas palestras e oficinas com os estudantes da comunidade e suas respectivas respostas. Inicialmente, procurou-se diagnosticar as ocorrências da alagamentos e inundações na comunidade. Observam-se que 24\% afirmam ter tido a residência alagada e $16 \%$ inundada e uma pequena parcela da amostra não conseguiu identificar as ocorrências desses dois desastres naturais. Após as capacitações a maioria dos participantes afirmam a importância do trabalho com os temas de Defesa Civil e GIRD (89\%) abordando-se temas transversais como climatologia, mudanças climáticas e educação ambiental e ainda afirmam que os conteúdos trabalhados ajudam na prevenção e mitigação dos efeitos dos desastres naturais nas comunidades (Fig. 9d).

\section{Considerações Finais}

No ensino fundamental de Fortaleza/CE os professores se deparam com disciplinas e discussões sobre clima, climatologia e mudanças climáticas e afirmam não estarem preparados para essa tarefa, parte por conta da

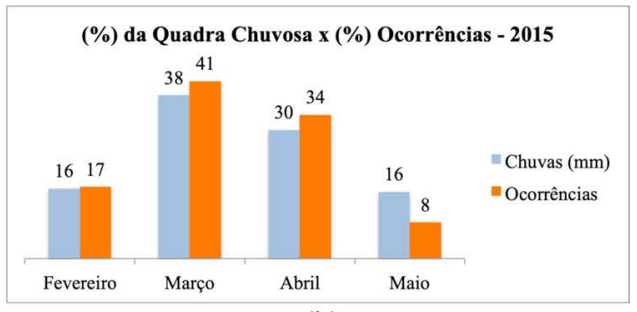

(b)

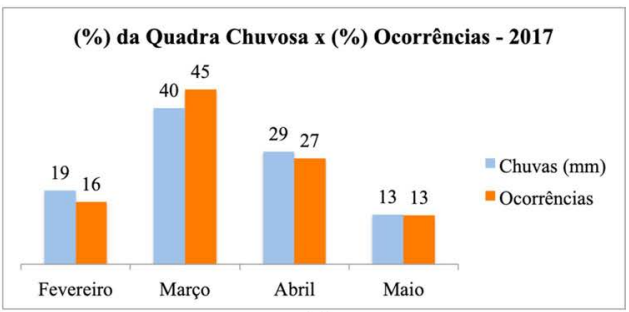

(d)

Figura 6 - Percentual das chuvas mensais em relação ao total da quadra chuvosa e o percentual das ocorrências mensais em relação ao total do período (2014 a 2017). 


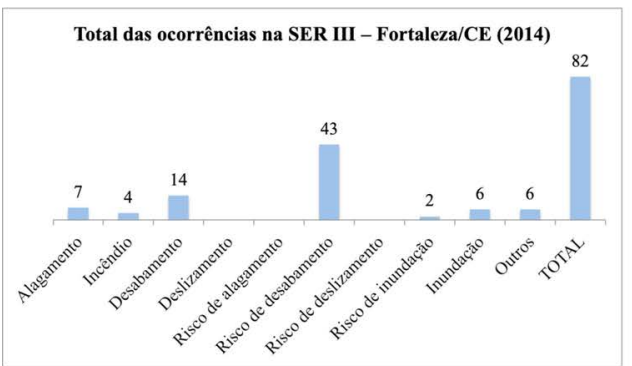

(a)

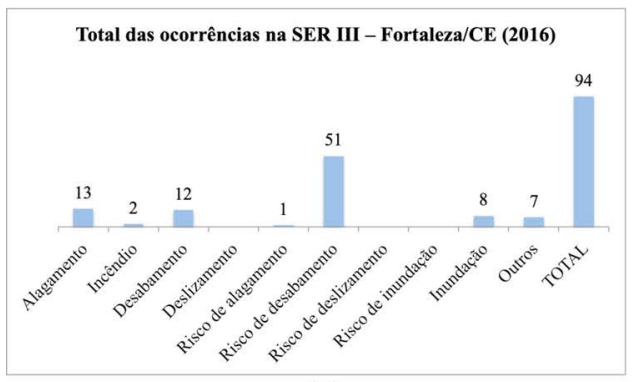

(c)

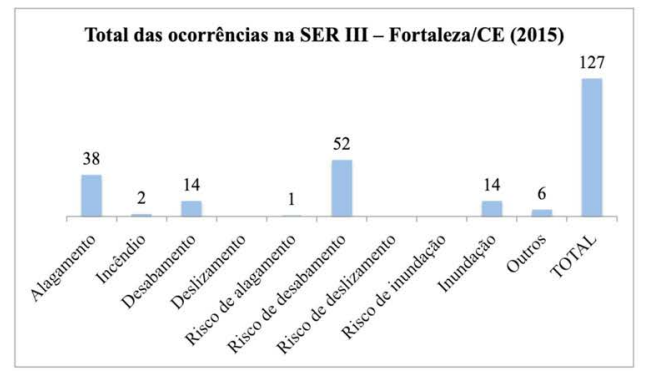

(b)

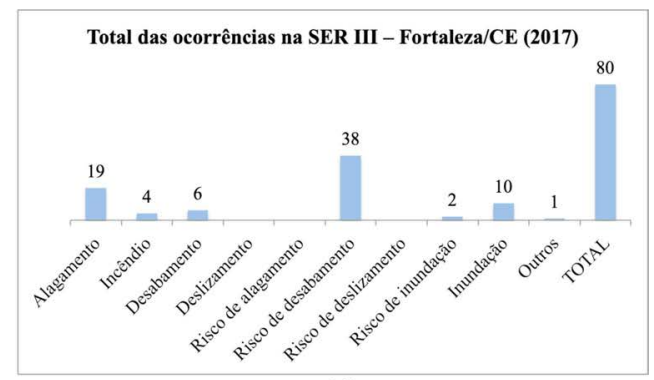

(d)

Figura 7 - Número das ocorrências mensais dos desastres no período da quadra chuvosa dos anos de 2014 a 2017 na região da SERIII em Fortaleza/CE.

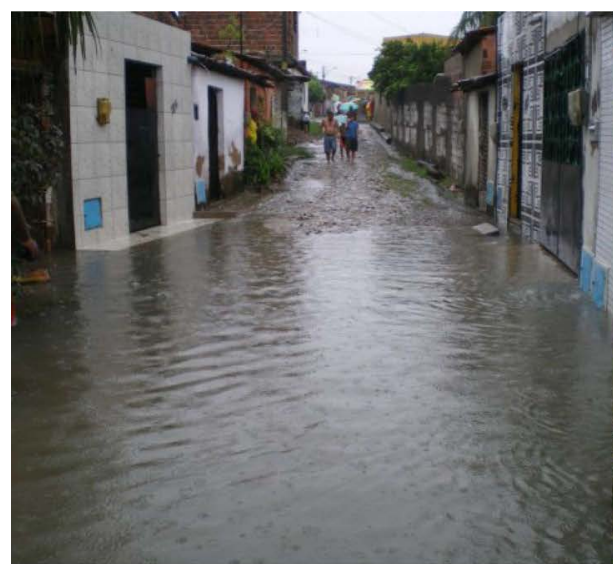

(a)

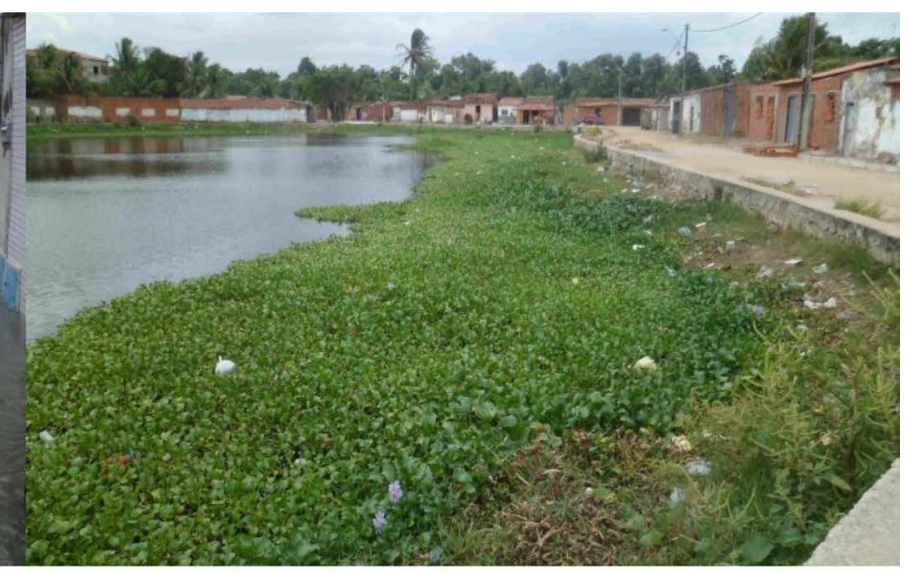

(b)

Figura 8 - Fotos das áreas de riscos nas regiões em estudo (a) região do Rio Maranguapinho (Região V) e (b) Alagamento após inundação na região da Ilha Dourada.

formação na universidade e também por falta de material bibliográfico e eventos que motivem o trabalho com a temática.

Em adição, a maioria dos estudantes participantes das pesquisas $(78 \%$ ) afirmam a importância de se trabalhar em sala de aula os conteúdos e temas transversais que abordam a temática do clima e dos desastres naturais, também por conta de terem suas moradias em áreas de riscos, classificadas pela Defesa Civil de Fortaleza/CE.

Os livros didáticos propostos pelo PNLD foram avaliados com foco na temática estudada, a maioria dos estudantes afirmam a importância dos conteúdos, porém, mencionam não ter facilidades em compreendê-los, resultado que corrobora com a avaliação dos professores que, em maioria, não estão satisfeitos com os conteúdos apresentados nesses livros propostos.

Em nível superior, a formação do licenciado em Geografia, em geral, contém uma disciplina de Meteorologia e/ou Climatologia, como é o caso da UECE. Assim, a hipótese é que essa formação tenha reflexo nos resultados obtidos que mostram, em geral, as afirmativas sobre o conhecimento dos conteúdos contidos nessa temática e a aceitação da implementação dos conteúdos da GIRD na grade curricular do curso.

Em relação aos diagnósticos dos desastres naturais na região, os resultados mostram um concordância, 


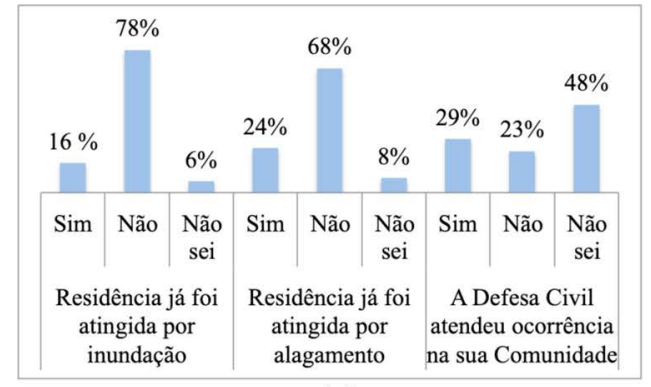

(a)

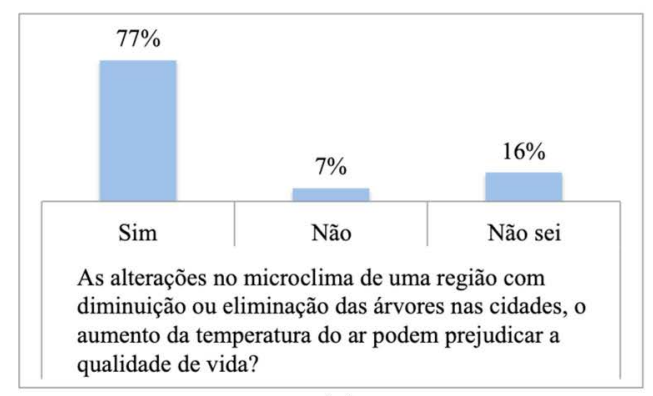

(c)

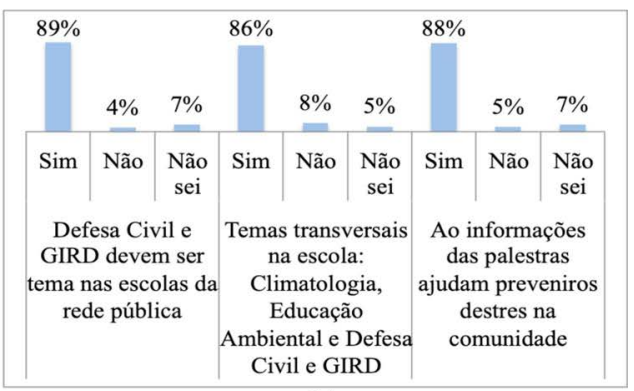

(b)

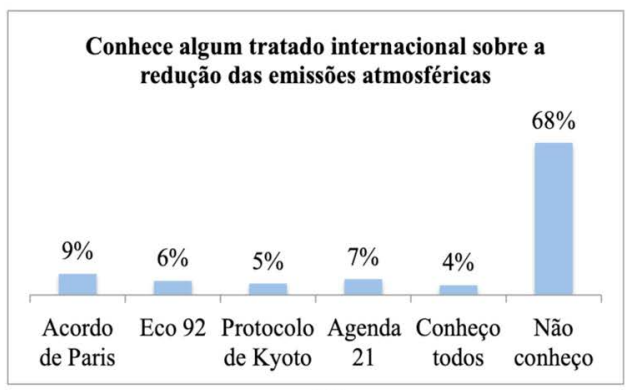

(d)

Figura 9 - Respostas dos 160 estudantes que participaram das palestras e oficinas de capacitação em Defesa Civil e GIRD.

correlação estatística classificada como forte, entre o aumento das chuvas na região e aumento das ocorrências de alagamentos e inundações em Fortaleza/CE e em particular na área de risco Ilha Dourada. Neste caso, observouse uma particularidade no ano de $2017 \mathrm{em}$ que obteve-se desvio positivo das chuva em relação a média climatologia da região e menor número geral de ocorrências, apesar de 19 casos de alagamentos que potencialmente trariam consequência e outras ocorrências.

Acredita-se que o resultado das ocorrências em 2017 é consequência do trabalho desenvolvido pelo agentes de defesa civil do munícipio na região. Trabalho que contou com a parceria da universidade (UECE) com a promoção das palestras e oficinas para as comunidades, corroborando com as ideias apresentadas pelos autores citados no trabalho (Ayoade, 2006; Steinke e Dantas, 2016).

Por fim, conclui-se que, as formações acadêmica, nas escolas e comunidades, exercem um papel fundamental para que as pessoas possam compreender a relação existente entre as variações do clima global e regional e os desastres naturais que afetam suas vidas em comunidade $\mathrm{e}$ que o conhecimento dessa relação pode contribuir para uma cultura de defesa civil, proposto por Calheiros (2009), e para que possam participar da GIRD em seus diversos níveis de decisões e do planejamento das políticas públicas de enfrentamento das consequências e dos efeitos desses desastres, concordando com Barcellos (2016).

\section{Referências}

AMARAL, R.; GUTJAHR, M.R. Desastres naturais. São Paulo: IG/SMA. 2011.

AYOADE, J.O.; SANTOS, M.J.Z.; BASTOS, S. Introdução à Climatologia para os Trópicos. 11a ed. Rio de Janeiro: Bertrand Brasil, 2006.

BARCELLOS, P.C.L.; SILVA, F.P.; VISSIRINI, F.S.B.; MAGALHÃES, C.A.; TERRA, J.M.; DUTRA, M.R.F.; AMARAL, I.C.F. Diagnóstico Meteorológico dos Desastres Naturais Ocorridos nos Últimos 20 Anos na Cidade de Duque de Caxias. Rev. Bras. Meteorol., v. 31, n. 3, p. 319329, 2016.

BARBOSA, M.E.; OLIVEIRA, A.O.S.A. Climatologia e internet: análise e proposta metodológica para o ensino de Geografia no ensino médio. Revista Geonorte, Edição Especial 2, v.1, n. 5, p. 108-120, 2012.

CALHEIROS, L.B. Conferência Geral sobre Desastres. Ministério da Integração Nacional, Brasília-DF, 2009.

CARVALHO, C.S.; MACEDO, E.S.; Ogura, A.T. (orgs). Mapeamento de Riscos em Encostas e Margem de Rios. Brasilia. Ministério das Cidades, Instituto de Pesquisas Tecnológicas, 176 pp, 2007.

CASTRO, A.L.C.; CALHEIROS, L.B. Manual de Medicina de Desastres. v. 1. Brasília: MI, 2007.

CAVALCANTI, L.S. O Ensino de Geografia na Escola. Campinas, SP: Papirus, 2012.

DANTAS, S.P. O Ensino de Climatologia Geográfica: uma abordagem de intervenção sobre os conceitos básico de Clima e Tempo. Revista de Geociências do Nordeste. v. 2, n. Especial, 2016.

Devore, J.L. Probability and Statistics for Engineering and the Sciences (8th Edition), Cengage Learning, Boston, USA, 2011. 
FORTUNA, D. As abordagens da climatologia nas aulas de geografia do ensino fundamental (segundo segmento): primeiras impressões. In: $4^{0}$ Seminário de Pesquisa do Instituto de Ciências da Sociedade e Desenvolvimento Regional, Universidade Federal Fluminense, Campos dos Goytacazes, RJ, 2010, p. 10.

JULIÃO, R.P.; NERY, F.; RIBEIRO, J.L.; BRANCO, M.C.; ZERERE, J.L. Guia Metodológico para a Produção de Cartografia Municipal de Risco e para a Criação de Sistemas de Informação Geográfica (SIG) de Base Municipal. ANPC, Lisboa, 2009.

KUBO, O.; BOTOMÉ, M. Ensino-aprendizagem: uma interação entre dois processos comportamentais. Interação em Psicologia, v. 5, n. 1, 2001.

MELO, D.M. Aprendizagem de Climatologia em Geografia no Ensino Médio Fundamentada na Teoria de Ausubel. Dissertação de Mestrado em Geografia, Centro de Filosofia e Ciências Humanas, Universidade Federal de Santa Catarina, Florianópolis, 2015.

MENEGUZZO, I.S.; MENEGUZZO, P.I. Os conteúdos de climatologia nos livros didáticos de geografia do $6^{\circ}$ ano do ensino fundamental. In: Revista Didática Sistêmica, v. 12, p. 55-63, 2010.

NARVÁEZ, L.; LAVELL, A.; ORTEGA, G.P. La gestión del riesgo de desastres: um enfoque basado em procesos. Lima: PREDECAN. 2009.
MOTA, L.S. Pobreza invisibilizada e resistência: As favelas às margens de trilhos em Fortaleza - CE e a política de urbanização de área de risco. 2007. Dissertação (Mestrado em Geografia). UFPE, Recife, 2007.

OLIVEIRA, D.J.L.; CHAGAS, F.L.R.; ALVES, W. S. Os desafios de ensinar a climatologia nas escolas. In: II Congresso de Educação - A Formação de Professores: Uma Proposta de Pesquisa a partir da Reflexão Sobre a Prática Docente, Iporá, Goiás, Brasil, 2012.

SILVA, Emerson Mariano da et al. Uma aplicação de conjuntos difusos na otimização do prognóstico de consenso sazonal de chuva no Nordeste do Brasil. Rev. Bras. Meteorol., v. 22, n. 1, p. 83-93, 2007.

STEINKE, E.T. Prática Pedagógica em climatologia no ensino fundamental: sensações e representações do cotidiano. ACTA Geográfica, Ed. Esp. Climatologia Geográfica, p. 77-86, 2012.

TOMINAGA, L.K.; SANTORO, J.; AMARAL, R. (orgs.). Desastres Naturais: Conhecer para Prevenir. São Paulo: Instituto Geológico, 2009.

ZABALA, A. A Prática Educativa. Como Ensinar. Tradução Ernani F. da F. Rosa. Porto Alegre: ARTMED, 1998.

License information: This is an open-access article distributed under the terms of the Creative Commons Attribution License (type CC-BY), which permits unrestricted use, distribution and reproduction in any medium, provided the original article is properly cited. 